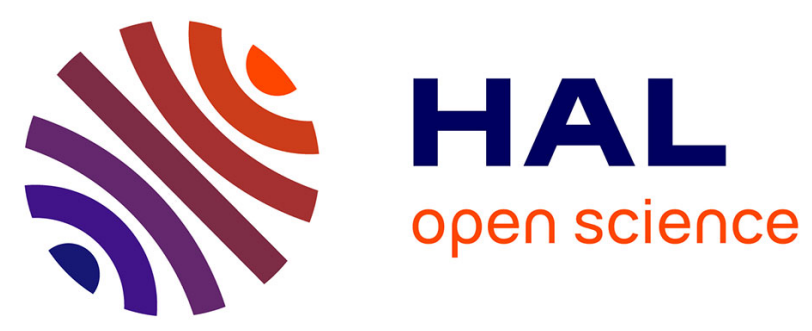

\title{
Factors associated with virological rebound in HIV-positive sub-Saharan migrants living in France after traveling back to their native country -ANRS-VIHVO 2006-2009 study
}

Jean-Médard Kankou, Olivier Bouchaud, Nathalie Lele, Marguerite Guiguet, Bruno Spire, Maria Patrizia Carrieri, Sophie Abgrall

\section{To cite this version:}

Jean-Médard Kankou, Olivier Bouchaud, Nathalie Lele, Marguerite Guiguet, Bruno Spire, et al.. Factors associated with virological rebound in HIV-positive sub-Saharan migrants living in France after traveling back to their native country -ANRS-VIHVO 2006-2009 study. Journal of Immigrant and Minority Health, 2019, 10.1007/s10903-019-00864-y • hal-02178772

\section{HAL Id: hal-02178772 \\ https://hal.sorbonne-universite.fr/hal-02178772}

Submitted on 10 Jul 2019

HAL is a multi-disciplinary open access archive for the deposit and dissemination of scientific research documents, whether they are published or not. The documents may come from teaching and research institutions in France or abroad, or from public or private research centers.
L'archive ouverte pluridisciplinaire HAL, est destinée au dépôt et à la diffusion de documents scientifiques de niveau recherche, publiés ou non, émanant des établissements d'enseignement et de recherche français ou étrangers, des laboratoires publics ou privés. 
Factors associated with virological rebound in HIV-positive sub-Saharan migrants living in France after traveling back to their native country - ANRS-VIHVO 2006-2009 study.

Jean-Médard Kankou ${ }^{1,2}$, Olivier Bouchaud MD $\mathrm{PhD}^{1,3}$, Nathalie Lele $\mathrm{MD}^{1}$, Marguerite Guiguet $\mathrm{PhD}^{4}$, Bruno Spire MD $\mathrm{PhD}^{5,6,7}$, Maria Patrizia Carrieri $\mathrm{PhD}^{5,6,7}$, Sophie Abgrall MD PhD ${ }^{8,9,10}$, and the ANRS-VIHVO Study Group*

${ }^{1}$ APHP, service de maladies infectieuses et tropicales, Hôpital Avicenne, Bobigny, France

${ }^{2}$ Laboratoire Parcours Santé Systémique, (PSS, EA 4129), Université Claude Bernard Lyon 1, Lyon, France

${ }^{3}$ Université Paris 13, Bobigny, France

${ }^{4}$ Université Pierre et Marie Curie, Sorbonne Universités, Univ Paris 06, INSERM, Institut Pierre Louis d'Epidémiologie et de Santé Publique (IPLESP UMRS 1136), F75013 Paris, France

${ }^{5}$ INSERM U912 (SE4S), Marseille, France

${ }^{6}$ Université Aix Marseille, IRD, Marseille, France

${ }^{7}$ ORS PACA, Observatoire Régional de la Santé Provences Alpes Côte d'Azur, Marseille,

France

${ }^{8}$ AP-HP, Service de Médecine interne/Immunologie clinique, Hôpital Antoine Béclère, Clamart, France, France

${ }^{9}$ Université Paris-Saclay, Univ. Paris-Sud, UVSQ, Le Kremlin-Bicêtre, France

${ }^{10}$ CESP INSERM U1018, Le Kremlin-Bicêtre, France.

*Membership of the VIHVO Study group is provided in the Acknowledgments.

Address for correspondence: Sophie Abgrall, $\mathrm{MD}, \mathrm{PhD}$,

Service de médecine interne, Hôpital Béclère

157 rue de la Porte de Trivaux, 93000 Clamart, France

Phone: + 331453741 51, fax: + 331453741 41,

E-mail: sophie.abgrall@aphp.fr

Conflicts of interest: no conflicts of interest.

Funding: ANRS (France Recherche Nord \& Sud Sida-HIV Hépatites). 


\section{ABSTRACT}

Background: In France, around 25\% of the estimated number of people living with HIV are migrants, of whom three quarters are from sub-Saharan Africa (SSA). Our objective was to determine factors associated with virological rebound (VR) at the occasion of a transient stay to the country of origin.

Methods: HIV-positive migrants from SSA participating to the ANRS-VIHVO adherence study between 2006-2009, on effective ART with controlled pre-travel HIV-1 plasma viral load (VL), were included. Outcome was VR, defined as $\mathrm{VL} \geq 50$ copies $/ \mathrm{mL}$ at the post-travel visit during the week following the return to France.

Results: Among 237 persons (61.6\% female, median age 41 years (IQR, 35-47), median time on ART 4.2 years (IQR, 2.2-7.1), 27 (11.4\%) experienced VR. The main purpose of the travel was to visit family and median time spent abroad was 5.3 weeks (IQR, 4.1-8.8). The travel was extended longer than anticipated by at least one week in 42 individuals (17.7\%). In multivariable logistic model, risk factors for VR were male sex (adjusted OR (aOR) 5.1; 95\%CI 1.6-16.2)), no employment in France (aOR 2.0; 1.2-3.5), self-reported non-adherence during the trip (aOR 14.9; 4.9-45.9) and PI-containing regimen (aOR 4.6; 1.2-17.6). In another analysis not including self-reported adherence, traveling during Ramadan while respecting the fast (aOR 3.3; 1.2-9.6) and extension of the stay (aOR 3.0; 1.1-7.8) were associated with VR.

Conclusions: Virological rebound was partly explained by structural barriers to adherence such as extension of the travel and inadequate management of Ramadan fasting. Individuals' journeys should be carefully planned with health care providers.

Keywords: HIV, antiretroviral therapy, virological rebound, migrant, travel, sub-Saharan Africa. 


\section{INTRODUCTION:}

In France, around 35000 migrants were thought to live with HIV in France in 2010, of whom $76 \%$ of female and $69 \%$ of male were actually diagnosed, representing $25 \%$ of the 148900 estimated number of people living with HIV [1]. Migrants from sub-Saharan Africa represented three quarters of migrants living with HIV [2]. HIV-positive migrants living in France who travel back to their native country are more exposed to health difficulties in relation to their trip, i.e. infectious tropical diseases [3-5] or decreased adherence [6-10]. Many reasons have been mentioned to explain decreased adherence in HIV-positive people traveling to tropical countries to visit friends and relatives: nondisclosure and fear of stigmatization [79], lack of enough treatment during the stay because of lack of enough medications supply before departure when travel is not anticipated or is unexpectedly lengthened [9], impaired intake because of digestive intolerance if a tropical disease occurs [3]. On the other hand, there is a need to maintain virological suppression to prevent sexually transmission of HIV to the spouse during the travel. A previous analysis of the ANRS-VIHVO cohort showed $11.5 \%$ of reduced reported adherence to ART in HIV-positive sub-Saharan migrants previously adherent to their antiretroviral therapy who travelled to their country of origin [9]. The impact of this self-reported lack of adherence on viral suppression was still to be investigated as well as the role of barriers to adherence. We aimed to assess factors associated with virological rebound in individuals included in the ANRS-VIHVO study who had an undetectable viral load before the trip.

\section{MATERIALS AND METHODS}

\section{Design \& Population}

Between 2006 and 2009, the ANRS-VIHVO study enrolled, in 24 French university participating centers, 268 HIV-1-positive native sub-Saharan African persons living in France, aged at least 18 years, who planned to visit their native country for a period between two weeks and six months within the next 8 weeks. All had a plasma viral load (pVL) below 200 copies/ml and were on ART combination, containing at least three antiretroviral drugs with at least a protease inhibitor (PI) or a non-nucleoside reverse transcriptase inhibitor (NNRTI), unchanged for at least three months prior to enrollment. For the present study, we selected individuals who were enrolled while their pVL was below 50 copies/ml: 237 individuals were included. 
Medical and social data were collected at enrollment, at a post travel visit during the week following the return to France and at a third visit 8 to 12 weeks after the return to France. Demographic, social, clinical, and immuno-virological data were retrieved from the participants' medical records. Self-administered questionnaires, previously validated among migrants in France [11], administered at enrollment and during the week following the return to France, collected information about adherence to cART in the 4 days and in the 4 weeks preceding enrollment while in France or the day back to France while travelling [9]. At each assessment, people were classified into two categories: adherent group (with high or moderate adherence, i.e. $80-100 \%$ of prescribed tablets taken) and non adherent group ( $<80 \%$ of prescribed tablets taken), as described elsewhere [9]. Because of the 6 months limit for the travel duration and the French rules for drug delivery, participants had the possibility to leave France with the whole antiretroviral stock required for the full duration of their trip.

\section{Statistical analyses}

Virological rebound was defined by $\mathrm{pVL} \geq 50$ copies/ml at the post-travel visit during the week following the return to France [12-13]. Potential correlates of virological rebound considered for the study were gender (male vs female), age, CD4 cell count before the travel ( $\geq 350$ vs $<350$ ), AIDS status, time since ART initiation, ART regimen (PI vs. NNRTI), literacy level (can read and/or write French vs. cannot read or write French), employment (unemployed vs. employed either in the formal or in the informal sector), lodging during the trip (with the steady partner vs. other), trip extension for at least one week, unexpected traumatic troubles during the stay, including political, natural, accidental (road injury, theft), familial ones (bereavement, moral pressure, conflicts), period of traveling (during the Ramadan fasting while respecting the fast), self-reported adherence during the trip (adherence vs. non-adherence). Quantitative variables were dichotomized according to the median value except for CD4 cell count which was dichotomized according to the threshold value recommended in national and international guidelines for ART initiation at the time of the study [14-15].

Statistical differences between people who remained with $\mathrm{pVL}<50$ copies/ml and people with a virological rebound after their travel were evaluated using Fisher's exact test for categorical variables and Wilcoxon-Mann-Whitney test for quantitative variables. Multivariable logistic regression models were used to assess potential factors associated with virological rebound including all variables possibly associated with the outcome of interest in the univariable analyses $(\mathrm{p}<0.15)$. A backward stepwise selection was used to select the final multivariable 
model. All variables possibly associated $(\mathrm{p}<0.15)$ with virological rebound in the univariable analyses were first included. Then variables with the highest Type III p-value were iteratively removed until no variable was left. The final model was the model with the lowest Akaike Information Criterion (AIC). Two multivariable analyses were separately investigated, one with and one without self-reported adherence status during the trip. Stata statistical software version 12 was used to perform the analyses.

\section{Ethics}

This study was approved by the institutional ethics committees, Direction Générale de la Santé and Comité de Protection des Personnes de la Pitié- Salpêtrière, at the session of 26/04/2006. All individuals received written information, provided signed consent to participate in the cohort study and were informed of their right to prevent their personal data from being used.

\section{RESULTS}

Of the 268 participants enrolled in the VIHVO study, 237 individuals (88.4\%) with pVL below 50 copies $/ \mathrm{ml}$ at the enrollment visit were included in the present study. Characteristics of the study population are summarized in table 1. Almost two thirds of the participants were female. Median age was 41 years (interquartile range (IQR), 35-47). Median time since HIV diagnosis was 5.3 years (IQR, 3.0-8.2), since ART initiation 4.2 years (IQR, 2.2-7.1) and since the first date with durable undetectable VL, i.e. last period of follow-up with no VL $\geq$ 200 copies/ml before the pre-travel visit, 2.2 years (IQR, 1.2-3.8). Median CD4 cell count before the travel was $440 / \mathrm{mm} 3$ (IQR, 336-575) and 70\% of the participants had more than $350 \mathrm{CD} 4$ cells $/ \mathrm{mm} 3$. Social characteristics in France were as follows: 164 (69\%) reported being owners or renters of their home in France, 147 (62\%) were employed, 114 (50\%) were married or living in a stable relationship.

One hundred and fifteen (49\%) participants traveled to Central Africa, 109 (46\%) to West Africa and $13(5 \%)$ to East Africa. The main purpose of the trip was to meet their family for the vast majority (232 participants, 98\%), and accommodation while abroad was at their spouse's for $32(14 \%)$, at their family's house for $144(60 \%)$ or in their own personal housing (owned or long-term rented accommodation) where their family usually lives for 29 (12\%), friends or other for $32(14 \%)$. Participants who lived at their spouse's were more frequently men $(21 / 32,66 \%)$ and participants who lived at their family's or friends' house were more 
frequently women $(135 / 205,66 \%)(\mathrm{p}=0.004)$. Median number of people living in the same house was 5 (IQR, 4-8).

The median time spent abroad was 5.3 weeks (IQR, 4.1 - 8.8). However, 42 participants $(17 \%)$ extended their stay at least one week longer than originally planned, median duration of extension 2.3 weeks (IQR, 1.7 - 5.4). Three individuals extended their stay for more than 6 months (11, 14 and 15 months). There was no difference in extending the stay between people with an employment and people with no employment (24/147 vs 18/90, p=0,49). During the stay, 82 individuals $(34.6 \%)$ reported at least one medical event during the trip, ie. malaria, digestive disorders, respiratory disorders, skin disorders, isolated fever, neurological disorders, miscellaneous, 56 individuals (23.6\%) reported at least one traumatic event during the trip and 10 individuals $(4.7 \%)$ used traditional medicine (herbal preparations, marabouts, traditional healers).

\section{Virological rebound:}

Among the 237 participants, $27(11,4 \%)$ had $\mathrm{pVL} \geq 50$ copies/ml when they returned to France with a median pVL of 755 copies/ml (IQR, 169 - 72 106), among whom 12 participants still had VL > 50 copies/ml (median 205 copies/ml, IQR, 94 - 2 599) at the subsequent study visit between 8 and 12 weeks after the return to France. Median (IQR) pVL during the week following the return to France was 13375 copies/ml (550-107 360) for these 12 participants and 269 copies/ml (IQR, 76-52 460) for the 15 participants who subsequently had $\mathrm{pVL}<50$ Copies/ml ( $\mathrm{p}<0.001)$. Subsequent undetectable pVL occurred in 9 among 14 individuals with $\mathrm{pVL}<1000$ copies/ml during the week following the return to France and in 6 among 13 individuals with $\mathrm{pVL} \geq 1000$ copies/ml $(\mathrm{p}=0.45)$. Antiretroviral therapy was unchanged for all individuals.

Results of univariate and multivariable analyses are shown in table 2. Virological rebound occurred in 8/32 (25.0\%) individuals who were hosted by their spouse, 12/144 (8.3\%) individuals hosted by their family, $3 / 29$ (10.3\%) individuals living in their own personal housing, 4/32 (12.5\%) individuals living at friend's or other. In the multivariable logistic model, male sex (adjusted OR (aOR) 5.1; 95\%CI 1.6-16.2), being unemployed (aOR 2.0; 95\%CI 1.2-3.5), PI-containing regimen (aOR 4.6; 95\%CI, 1.2-17.6 for PI versus NNRTI) and self-reported non-adherence during the trip (aOR 14.9; 95\%CI 4.9-45.9) were associated with virological rebound. When self-reported adherence was removed from the model, traveling during the Ramadan period while respecting the fast (aOR 3.3; 95\%CI 1.2-9.6) and extension 
of the stay (aOR 3.0; 95\% CI 1.1-7.8) were the trip determinants associated with virological rebound.

\section{DISCUSSION}

Factors associated with virological rebound after travel were assessed among HIV-positive individuals originating from sub-Saharan Africa, living in France and successfully treated with ART for a median of 4 years. Among the 237 individuals included in the study, $11 \%$ had $\mathrm{pVL} \geq 50$ copies/ml when they returned to France of whom about half had a controlled viral load at a subsequent visit 8 to 12 weeks after the return. Risk factors for virological rebound were male sex, no employment in France, PI-containing regimen and self-reported nonadherence during the stay abroad. In models not including self-reported adherence, unexpected extension of the stay and travelling during Ramadan while respecting the fast were associated with virological rebound.

Our study had some limitations. First, virological rebound, defined using a single viral load measurement at the time of the post-travel visit, included both individuals with a sustained virological rebound and individuals with a blip of viral replication. Indeed, 9 individuals among 14 with $\mathrm{pVL}<1000$ copies/ml during the week following the return to France who had a subsequent undetectable pVL could be considered to have a simple blip, ie single detectable viral load < 1000 copies/ml not confirmed at the subsequent sample [13]. However, even low-level viraemia episodes have been shown to be associated with increased risk of antiretroviral drug resistance and virological failure $[16,17,18]$. Second, we did not have data to assess viral replication during the travel. No resistance tests were systematically performed but half of the participants with a virological rebound after the travel had a controlled viral load without a change in their antiretroviral therapy within the next two to three months. Last, we assessed only HIV-positive people originating from sub-Saharan Africa who had an undetectable viral load before the travel. However, in France in 2015, 89\% of men and 89\% of women originating from Sub-Saharan Africa on ART had an undetectable viral load, close to the numbers of $92 \%$ and $93 \%$ for men and women born in France respectively (FHDHANRS CO4 cohort, personal communication). Some studies have described adherence outcome associated with travel to the tropics [6-9,19-20], few have focused on migrants originating from SSA traveling back to their country of origin [7,9] and none assessed risk factors for virological rebound after their travel. 
A recent study has shown that region of origin but not travel per se was associated with a higher risk of virological rebound [10]. In this study, travel was a significant additional risk factor for virological rebound only in individuals originating from SSA but not in people from other origin, Western countries or other non-SSA countries. People visiting friends and relatives were at a higher risk for virological rebound but not frequent travelers, suggesting that the conditions of the travel rather than the travel per se affect the virological outcome during the travel [10]. Reasons for viral rebound were assessed in people living in Nigeria traveling for Hajj with antiretroviral interruption being mainly because of stigma in a congregational setting or failure to pass airport of departure or arrival with medications [19]. None of our study individuals reported having experienced difficulty when crossing the airports with their treatment. However, we did not question the experience of stigma in the community.

In our study, decreased self-reported adherence during the travel was associated with viral rebound. Although initial high levels of adherence during the first months of ART, ie $>95 \%$, are necessary to achieve viral suppression after ART initiation [21,22], long-term moderate adherence has a less negative impact in the current context of potent therapy after a previous long duration of continuous HIV suppression, ie for more than 12 months [21,23-25]. Severe deviations to adherence during the travel probably explained viral replication after the travel as indicated by the association with unexpected extension of stay or travel during Ramadan. Despite a low number of events, we found an association between PI-regimen and virological rebound compared to regimen containing NNRTI or NNRTI plus PI as previously shown, one hypothesis being a higher level of intolerance associated with PIs in tropical countries [2425]. It cannot be excluded that some ART regimens were more compatible with schedule modifications and food consumption during the Ramadan fasting [26].

Other factors of virological rebound during the travel were to be a male, and to be unemployed in France, a proxy of social condition. In our study, men had a three to five times higher aOR of virological rebound than women, contrary to other studies which also included men having sex with men [10,24,27]. Reasons for traveling back to the country of origin might have been different between men and women with men traveling more frequently to join their spouse or get married and women traveling more often to visit their relatives. Fear of stigma and HIV non disclosure could be risk factors, but as we were not able to differentiate disclosure in France and in the country of the travel we did not assess association between HIV non disclosure and post travel viral replication in our study [28]. 
In conclusion, although post travel viral rebound occurred in up to $11 \%$ of sub-Saharan HIVpositive migrants traveling to their native country, return to undetectability was rapid without any antiretroviral change for at least half of the individuals, probably because rate of resistance mutations acquisition is low after PI-containing cART interruptions [29]. Viral rebound was partly explained by structural barriers to adherence during travel such as extension of the stay and inadequate management of the Ramadan fasting. Individuals' journeys should be anticipated and carefully planned with health care providers, ensuring that they travel with enough medication so that any extension of their stay can be adequately managed. Ramadan fasting should also be anticipated with prescription of ad hoc drug combinations such as once daily dose and forgiving regimens. 


\section{Acknowledgements:}

We gratefully acknowledge the contributions of all clinical investigators of the VIHVO study: Michele Bentata (CHU Avicenne, Bobigny, France); Bruno Fantin (CHU Beaujon, Clichy, France); Cécile Goujard (CHU Bicêtre, Le Kremlin-Bicêtre, France); Sophie Matheron (CHU Bichat, Paris, France); Odile Launay (CHU Cochin, Paris, France); Vincent Le Moing (CHU de Montpellier, Montpellier, France); Olivier Lortholary (CHU Necker, Paris, France); PaulHenri Consigny (CHU Pasteur, Paris, France); Matthieu Saada (Hôpital de Perpignan, Perpignan, France); Christine Katlama, Anne Simon (CHU Pitié-Salpétrière, Paris, France); Cédric Arvieux (CHU de Rennes, Rennes, France); Pauline Campa, Pierre-Marie Girard (CHU Saint-Antoine, Paris, France); Marie-Aude Khuong (Hôpital De Lafontaine, SaintDenis, France); Jean-Michel Molina, Caroline Lascoux-Combe (CHU Saint-Louis, Paris, France); David Rey, Murielle Rondeau (Hôpital Civil, Strasbourg, France); Gilles Pialoux (CHU Tenon, Paris, France); Carine Couzigou, Daniel Vittecoq (CHU Paul Brousse, Villejuif, France); Olivier Patey (Hôpital de Villeneuve Saint Georges, Villeneuve saint Georges, France); Denis Malvy, Thierry Pistone, Philippe Morlat (CHU Bordeaux, Bordeaux, France); Michel Duong, Pascal Chavanet (CHU Dijon, Dijon, France). 


\section{References}

1. Supervie V, Marty L, Lacombe JM, Dray-Spira R, \& al. Looking Beyond the Cascade of HIV Care to End the AIDS Epidemic: Estimation of the Time Interval From HIV Infection to Viral Suppression. J Acquir Immune Defic Syndr 2016; 73: 348-355.

2. INVS. Infection par le VIH/SIDA et les IST. Point épidémiologique du 23 novembre 2015. http://invs.santepubliquefrance.fr/fr./Dossiers-thematiques/Maladies-infectieuses/VIH-sidaIST/Infection-a-VIH-et-SIDA/Actualites/Infection-par-le-VIH-SIDA-et-les-IST-Pointepidemiologique-du-23-novembre-2015.

3. Bhadelia N, Klotman M, Caplivski D. The HIV-positive traveler. Am J Med 2007; 120: 574-80.

4. Sherrard AW, McCarthy AE. Travel patterns and health risks for patients infected with HIV. Travel Med Infect Dis 2009; 7: 291-5.

5. Péres-Molina JA, Martinez-Perez A, Serre N, Trevino B, Ruiz-Giardin JM, et al. Characteristics of HIV infected individuals traveling abroad. Results from the +REDIVI Collaborative Network. Enferm Infecc Microbiol Clin 2016; 34: 108-13.

6. Salit IE, Sano M, Boggild AK, Kain KC. Travel patterns and risk behaviour of HIVpositive people travelling internationally. CMAJ 2005; 172: 884-8.

7. Sellier P, Clevenbergh P, Liubicic L, Simoneau G, Evans J, Delcey V, Diemer M, Bendenoun M, Mouly S, Bergmann JF. Comparative evaluation of adherence to antiretroviral therapy in sub-Saharan African native HIV-infected patients in France and in Africa. Clin Infect Dis 2006; 43: 654-7.

8. Woolley I and Baley C. Visiting friends and relatives may be a risk for non-adherence for HIV-positive travellers. Int J STD AIDS 2012; 23: 833-34.

9. Abgrall S, Fugon L, Lélé N, Carde E, Bentata M, Patey O, Khuong MA, Spire B, Carrieri P, Bouchaud O. Visiting One's Native Country: The Risks of Nonadherence in HIV-Infected Sub-Saharan Migrants - ANRS VIHVO Study. J Int Assoc Provid AIDS Care 2013; 12: 407 13.

10. Gebreselassie HM, Kraus D, Fux CA, Haubitz S, Scherrer A, et al. Ethnicity predicts viral rebound after travel to the tropics in HIV-infected travelers to the tropics in the Swiss HIV Cohort Study. HIV Medicine 2017; 18: 564-72.

11. Marcellin F, Carrieri MP, Peretti-Watel P; and the VESPA study group. Do migrants overreport adherence to highly antiretroviral therapies: results from the French VESPA (ANRS-EN12) national survey. J Acquir Immune Defic Syndr 2006; 42: 646-764. 
12. European AIDS Clinical Society (EACS). Clinical management and treatment of HIVinfected adults in Europe. http://infekt.ch/content/uploads/2013/11/HIVcup_EACS09_Battegay.pdf. Accessed 01/17/2017.

13. Morlat et le groupe d'experts sur l'infection à VIH. Prise en charge médicale des personnes vivant avec le VIH. Actualisation 2014 du rapport 2013. Sous la direction du $\mathrm{Pr}$ Philippe Morlat et sous l'égide du CNS et de l'ANRS. Nov 2014. 13-97. Available at: http://solidarites-sante.gouv.fr/IMG/pdf/experts-vih_actualisations2014.pdf

14. Yéni $\mathrm{P}$, et le groupe d'experts sur l'infection à VIH. Prise en charge médicale des personnes infectées par le VIH. 2006. Traitement antiretroviral: p22-44. Paris: Flammarion medicine- sciences 2006. Available at: http://www.sante.gouv.fr/IMG/pdf/rapport-experts2006/pdf.

15. Hammer SM, Saag MS, Schechter M, Montaner JS, Schooley RT, Jacobsen DM, et al. International AIDS Society-USA panel. Treatment for adult HIV infection: 2006 recommendations of the International AIDS Society-USA panel. JAMA 2006; 296: 827-843. 16. Vandenhende MA, Ingle SM, May M, et al. Impact of low-level viremia on clinical and virological outcomes in treated HIV-1 infected patients. AIDS 2015;29: 373-383.

17. Pernas B, Grandal M, Pertega S, et al. Any impact of blips and low-level viraemia episodes among HIV-infected patients with sustained virological suppression on ART? J Antimicrob Chemother 2016;71(4):1051-5.

18. Hermans LE, Moorhouse M, Carmona S, et al. Effect of HIV-1 low-level viraemia during antiretroviral therapy on treatment outcomes in WHO-guided South African treatment programmes: a multicentre cohort study. Lancet Infect Dis 2018;18(2):188-97.

19. Habib AG, Abdulmumini M, Dalhat MM, Hamza M, Iliyasu G. Anti-retroviral therapy among HIV infected travelers to Hajj Pilgrimage. J Travel Med 2010; 17: 176-81.

20. Taylor BS, Reyes E, Levine EA, Khan SZ, Garduño LS, Donastorg Y, Hammer SM, Brudney K, Hirsch JS. Patterns of geographic mobility predict barriers to engagement in HIV care and antiretroviral treatment adherence. AIDS Patient Care STDS 2014; 28: 284-295.

21. Carrieri MP, Raffi F, Lewden C, Sobel A, Michelet C, Cailleton V, Chene G, Leport C, Moatti JP, Spire B ; APROCO study group. Impact of early versus late adherence to highly active antiretroviral therapy on immuno-virological response : a 3-year follow-up study. Antivir Ther 2003; 8: 585-94. 
22. Paterson DL, Swindells S, Mohr J, Brester M, Vergis EN, Squier C, Wagener MM, Singh N. Adherence to protease inhibitor therapy and outcomes in patients with HIV infection. Ann Intern Med 2000; 133: 21-30.

23. Benzie AA, Bansi LK, Sabin CA, Portsmouth S, Hill T, Johnson M, Gilson R, Easterbrook P, Gazzard B, Fisher M, Orkin C, Dunn D, Delpech V, Taylor GP, Walsh JC, Phillips AN; United Kingdom Collaborative HIV Cohort (CHIC) Study Group. Increased duration of viral suppression is associated with lower viral rebound rates in patients with previous treatment failures. AIDS 2007; 21: 1423-1430.

24. Geretti AM, Smith C, Haberl A, Garcia-Diaz A, Nebbia G, Johnson M, Phillips P, Staszewski S. Determinants of virological failure after successful viral load suppression in first-line highly active antiretroviral therapy. Antivir Ther 2008; 13: 927-36.

25. Rosenblum M, Deeks SG, van der Laan M, Bangsberg DR. The risk of virologic failure decreases with duration of HIV suppression, at greater than $50 \%$ adherence to antiretroviral therapy. PLoS One 2009; 4(9): e7196.

26. Bragazzi NL, Briki W, Khabbache H, Rammouz I, Mnadla S, Demaj T, Zouhir M. Ramadan fasting and infectious diseases: a systematic review. J Infect Dev Ctries 2015; 9: 1186-94.

27. Lima VD, Bangsberg DR, Harrigan PR, Deeks SG, Yip B, Hogg RS, et al. Risk of viral failure declines with duration of suppression on highly active antiretroviral therapy irrespective of adherence level. J Acquir Immune Defic Syndr 2010; 55: 460-465.

28. Kankou JM, Bouchaud O, Lele N, Bourgeois D, Spire B, Carrieri MP, Abgrall S; and the ANRS-VIHVO study group. Factors associated with HIV status disclosure in HIV-infected sub-Saharan migrants living in France and successfully treated with antiretroviral therapy: results from the ANRS-VIHVO study. J Immigr Minor Health 2017; 19: 843-50.

29. Firnhaber C, Azzoni L, Foulkes AS, Gross R, Yin X, van Amsterdam D, et al. Randomized Trial of Time-Limited Interruptions of Protease Inhibitor-Based Antiretroviral Therapy (ART) vs. Continuous Therapy for HIV-1 Infection. PLoS One 2011;6(6):e21450. 
Table 1. Baseline characteristics of $237 \mathrm{HIV}$-positive migrants before traveling to sub-Saharan Africa

\begin{tabular}{lc}
\hline & N (\%) or Median [IQR] \\
\hline Male sex & $91(38.4)$ \\
Age (years) & $41.0[35.4-47.4]$ \\
Region of birth & \\
$\quad$ Central Africa & $117(49.4)$ \\
$\quad$ West Africa & $106(44.7)$ \\
$\quad$ East Africa & $14(5.9)$ \\
Region of care & $191(80.6)$ \\
$\quad$ Paris area & $46(19.4)$ \\
Other metropolitan area & \\
Literacy level & $31(13.1)$ \\
$\quad$ Unable to read or write French & $206(86.9)$ \\
$\quad$ Able to read and/or write French & $130(54.9)$ \\
Educational level* & $107(45.1)$ \\
$\quad$ Secondary school & \\
$\quad$ secondary school & $147(62.0)$ \\
Employment & \\
$\quad$ Yes (formal/informal) & $114(50.2)$ \\
Marital status & $32(14.1)$ \\
$\quad$ Married/living together & $81(35.7)$ \\
$\quad$ Divorced & $440[336-575]$ \\
Single & $68(28.7)$ \\
CD4 cell count (/mm $\left.{ }^{3}\right)$ & $4.2[2.2-7.1]$ \\
Previous AIDS & \\
Time since ART initiation (years) & $94(39.7)$ \\
ART regimen & $143(60.3)$ \\
$\quad$ NNRTI containing** & \\
$\quad$ PI containing & \\
\hline ART, antiretroviral thapy; NNRTI & \\
\hline
\end{tabular}

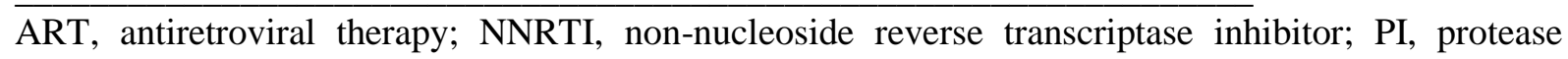
inhibitor; IQR, interquartile range.

* Secondary school is for people aged 11 and over

** Nine individuals with NNRTI + PI (for example, boosted darunavir + etravirine) 
Table 2. Factors associated with virological rebound (VL $\geq 50$ copies $/ \mathrm{mL}$ ) in 237 HIV-positive migrants after their travel to sub-Saharan Africa

\begin{tabular}{|c|c|c|c|c|c|}
\hline & $\begin{array}{c}\text { All } \\
\mathrm{N}=237)\end{array}$ & $\begin{array}{l}\mathrm{VL} \geq 50 \mathrm{cp} / \mathrm{ml} \\
\quad(\mathrm{n}=27)^{*}\end{array}$ & $\mathrm{p}$ & $\begin{array}{c}\text { Model } 1 \\
\text { aOR }(95 \% \mathrm{CI})\end{array}$ & $\begin{array}{c}\text { Model } 2 \\
\text { aOR }(95 \% \mathrm{CI})\end{array}$ \\
\hline \multicolumn{6}{|l|}{ At enrollment, before travel: } \\
\hline Sex Female & 146 & $12(8.2)$ & \multirow{2}{*}{0.051} & 1.00 & 1.00 \\
\hline Male & 91 & $15(16.5)$ & & $5.06(1.58-16.21)$ & $2.98(1.15-7.75)$ \\
\hline Age $<42$ years & 120 & $13(10.8)$ & \multirow[t]{2}{*}{0.784} & \multirow[t]{2}{*}{-} & \multirow{2}{*}{-} \\
\hline$\geq 42$ years & 117 & $14(12.0)$ & & & \\
\hline \multicolumn{6}{|l|}{ Literacy level } \\
\hline No reading or writing French & 31 & $8(25.8)$ & \multirow{2}{*}{0.013} & \multirow[t]{2}{*}{ NR } & \multirow[t]{2}{*}{ NR } \\
\hline Reading and/or writing French & 206 & $19(14.6)$ & & & \\
\hline \multicolumn{6}{|c|}{ Employment** } \\
\hline Yes (formal/informal) & 147 & $11(7.5)$ & \multirow{2}{*}{0.015} & 1.00 & \multirow{2}{*}{$\begin{array}{c}1.00 \\
2.17(1.32-3.58)\end{array}$} \\
\hline No & 90 & $16(17.8)$ & & $2.01(1.15-3.52)$ & \\
\hline \multicolumn{6}{|l|}{$\mathrm{CD} 4$ cell count $\left(/ \mathrm{mm}^{3}\right)$} \\
\hline$<350$ & 70 & $11(15.7)$ & \multirow{2}{*}{0.141} & \multirow{2}{*}{ NR } & \multirow{2}{*}{ NR } \\
\hline$\geq 350$ & 167 & $16(9.6)$ & & & \\
\hline \multicolumn{6}{|l|}{ AIDS Status } \\
\hline No & 169 & $15(8.9)$ & \multirow[t]{2}{*}{0.055} & \multirow[t]{2}{*}{ NR } & \multirow[t]{2}{*}{ NR } \\
\hline Yes & 68 & $12(17.6)$ & & & \\
\hline \multicolumn{6}{|l|}{ Time since ART initiation (years) } \\
\hline$<5$ & 138 & $18(13.0)$ & \multirow[t]{2}{*}{0.359} & \multirow[t]{2}{*}{-} & \multirow[t]{2}{*}{-} \\
\hline$\geq 5$ & 98 & $9(9.2)$ & & & \\
\hline \multicolumn{6}{|l|}{$\mathrm{ART}^{-}$} \\
\hline NNRTI**** & 94 & $4(4.3)$ & 0.015 & 1.00 & 1.00 \\
\hline PI & 143 & $23(16.1)$ & & $4.63(1.22-17.64)$ & $3.87(1.24-12.06)$ \\
\hline During the trip: & & & & & \\
\hline Lodging & & & & & \\
\hline Family, friends, other & 205 & $19(9.3)$ & 0.016 & NR & NR \\
\hline Steady partner & 32 & $8(25.0)$ & & & \\
\hline Extension of stay & & & & & \\
\hline No & 195 & $17(8.7)$ & 0.013 & NR & 1.00 \\
\hline Yes & 42 & $10(23.8)$ & & & $3.00(1.14-7.79)$ \\
\hline Traumatic troubles during stay** & $* * *$ & & & & \\
\hline No & 181 & $17(9.4)$ & 0.081 & NR & NR \\
\hline Yes & 56 & $10(17.9)$ & & & \\
\hline Medical events during stay & & & & & \\
\hline No & 155 & $15(9.7)$ & 0.253 & - & - \\
\hline Yes & 82 & $12(14.6)$ & & & \\
\hline $\begin{array}{l}\text { Traveling during the Ramadan pe } \\
\text { while respecting the fast }\end{array}$ & eriod & & & & \\
\hline Not concerned/out of period & d 198 & $18(9.1)$ & 0.023 & NR & 1.00 \\
\hline Concerned & 39 & $9(23.1)$ & & & $3.32(1.15-9.59)$ \\
\hline Self-reported adherence & & & & & \\
\hline Yes & 187 & $10(5.4)$ & $<0.01$ & 1.00 & - \\
\hline No & 30 & $13(43.3)$ & & $14.91(4.85-45.86)$ & \\
\hline
\end{tabular}

$\overline{\text { ART, antiretroviral therapy; NNRTI, non nucleoside reverse transcriptase inhibitor; PI, protease }}$ inhibitor; IQR, interquartile range; OR, odds ratio; NR, not retained in the final model.

* Values in the column are numbers (percentages)

** either part-time or full-time 
*** Nine individuals with NNRTI + PI, one of these nine had a virological rebound **** Troubles included political, natural, accidental (road injury, theft) and familial (bereavement, moral pressures, conflicts) 